Www.jmscr.igmpublication.org

Impact Factor (SJIF): 6.379

Index Copernicus Value: 79.54

ISSN (e)-2347-176x ISSN (p) 2455-0450

crossrefDOI: https://dx.doi.org/10.18535/jmscr/v6i12.154

Journal Of Medical Science And Clinical Research

\title{
Easy way of Converting Dental Micro drill in to Neuro Surgical Craniotome by attaching custom made dural guard- A Matter of Hundred Rupees
}

\author{
Authors
}

\author{
P. Pallavan M.ch. ${ }^{1}$, P. Mannar Mannan Mch. ${ }^{2}$, Dhiraj Patil Sunil Mch. ${ }^{3}$ \\ Prof. M.M. Sankar $\mathrm{Mch}^{4}$, S. Rajkumar Mch \\ ${ }_{1,2,3}$ Neuro Surgery Post graduate \\ Research performed at Government Stanley Medical College, Chennai, Tamilnadu, India
}

\begin{abstract}
For doing craniotomy/craniectomy Hand driven HUDSON BRACE, electrical, Battery neuro drills are commonly used in neurosurgery. Neurosurgeons working in peripheral hospitals particularly developing country like India could not afford commercially available Neuro drills because of the high cost or non availability or poor quality. Dental micro drill with custom made dural guard attachment is a viable alternative to sophisticated Neurosurgical drill with craniotome. Availability, low cost, maintenance, service, durability consider the dental micro drill system as the cost effective equipment in neurosurgery.

Keywords: craniotomy, cranictomy, Hudson brace, neuro drill, Dental micro drill, Dural guard.
\end{abstract}

\section{Introduction}

Power tools form the back bone of modern neurosurgical procedures particularly for opening skull bone in craniotomy and craniectomy and should be consider as third arm for operating neuro surgeons. There are three types of craniotomy instruments are commonly used in Neurosrgical procedures at present: manual, electric and high speed micro Neuro drills. micro drill is having several advantages over other drills because of its simplicity, portability and lesser weight. But unfortunately commercially available high speed micro neuro drill is very costly even though we are living in the era of Robot drill and this article discusses the use of low cost dental micro drill as craniotome with custom made dural guard as viable alternative to other neuro drills in developing countries.

\section{Technical note}

Electrical micro drill system consist of power supply with speed control box, foot operated switch, micro motor, clinical hand piece for attaching drill bits and burrs. The brushed motors having RPM of 35000, 45 watts, torque of 240 gf.Cm, very cheap and fit for cutting bone. High speed brushless motors are costlier and over engineered for developing countries. Motors with same specification used in dental lab for grinding metals, ceramics and dental implants. Since skull bone is softer than dental implants we consider dental clinical micro motor drill system suitable for cranial surgery with custom modification. More over dental drills are commonly used in ENT surgeons for bone drilling and burring.

High speed neuro drill also having same parts of dental drill except craniotome attachment. 
Craniotome attachment is having straight flute side cutting cylindrical type of router burr rotates at the centre of dural guard. Dural guard With the use of modern types of cranial drills, surgeons are able to create holes in the bone structure without traumatizing underlying brain tissue. ${ }^{[6]}$ The drill's working tool tip consists of a spiral blade that is framed by a guard device with an angled cranium guide that rests against the inner layer of the skull bone. The dura guard pushes the dura mater downward while the craniotome is moved forward thus preventing dural tearing.

Parts of dural guard are hallow cylindrical body with side stem with terminal foot plate. cylindrical body snugly fit with the nose of hand piece. the side stem is smaller in diameter of side cutting burr used. The foot plate is having small notch which fit loosly with the side cutting burr

We custom made dural guard with stainless steel material with the help of local engineering facility. The outer diameter of body of dural guard is $10.5 \mathrm{~mm}$, inner diameter is $9.1 \mathrm{~mm}$ which snugly fit with the nose cone of dental clical hand piece with $9 \mathrm{~mm}$ diameter outer diameter. Total length is $35 \mathrm{~mm}$ with $2 \mathrm{~mm} / 2 \mathrm{~mm}$ squire notch at the upper end for coupling with the nose cone of hand piece which prevents rotation of dura guard. For additional stability having threaded hole for 3,5 $\mathrm{mm}$ Phillips head screw along stem aspect of cylindrical body. the side stem is $2 \mathrm{~mm}$ thickness at side to sde and $3 \mathrm{~mm}$ thickness front to back, $15 \mathrm{~mm}$ in length. The foot plate dimentions are $3 \mathrm{~mm}$ breath $6 \mathrm{~mm}$ length and $2 \mathrm{~mm}$ height. 2.35 $\mathrm{mm}$ cylindrical metal burr with straight flutes available in dental surgical store is used as side cutting burr 14 cranial surgeries. with this instrument since This is autoclavable material the results are good
Table 1 comparative study of neurodrill and dental microdrill

\begin{tabular}{|c|c|c|c|}
\hline No. & parameter & Neuro drill & Dental micro drill \\
\hline 1 & cost & $\begin{array}{l}\text { Very high } \\
\text { around } 14 \\
\text { lacks } \\
\end{array}$ & Around 5000 \\
\hline 2 & Speed in RPM & $0-80000$ & $\begin{array}{ll}0- & 35000\end{array}$ \\
\hline 3 & Motor & brushless & Carbon brushed \\
\hline 4 & torque & $1-9.9 \mathrm{Ncm}$ & $\begin{array}{l}240 \text { gf.cm }(2.35 \\
\text { newton) }\end{array}$ \\
\hline 5 & watts & 16 & 45 \\
\hline 6 & $\begin{array}{l}\text { Vibration } \\
\text { during } \\
\text { operation } \\
\end{array}$ & negligible & minimal \\
\hline 7 & availability & $\begin{array}{c}\text { On order and } \\
\text { wait }\end{array}$ & Readily available \\
\hline 8 & maitainance & complicated & simple \\
\hline 9 & Repair & $\begin{array}{c}\text { Authorised } \\
\text { dealer }\end{array}$ & $\begin{array}{l}\text { All dental surgical } \\
\text { shops }\end{array}$ \\
\hline 10 & weight & $\begin{array}{l}\text { Light weght } \\
\text { drill large big } \\
\text { console } \\
\end{array}$ & $\begin{array}{l}\text { Light weight with } \\
\text { small console }\end{array}$ \\
\hline \multicolumn{4}{|l|}{11} \\
\hline 12 & sterilisation & $\begin{array}{c}\text { Autoclavable } \\
\text { motor and } \\
\text { hand piece }\end{array}$ & $\begin{array}{c}\text { Motor needs } \\
\text { formaline chamber, } \\
\text { hand piece can be } \\
\text { autoclaved }\end{array}$ \\
\hline
\end{tabular}

Ncm- newton centimetre; rpm-rotation per minute; gf.cmgram force centimetre

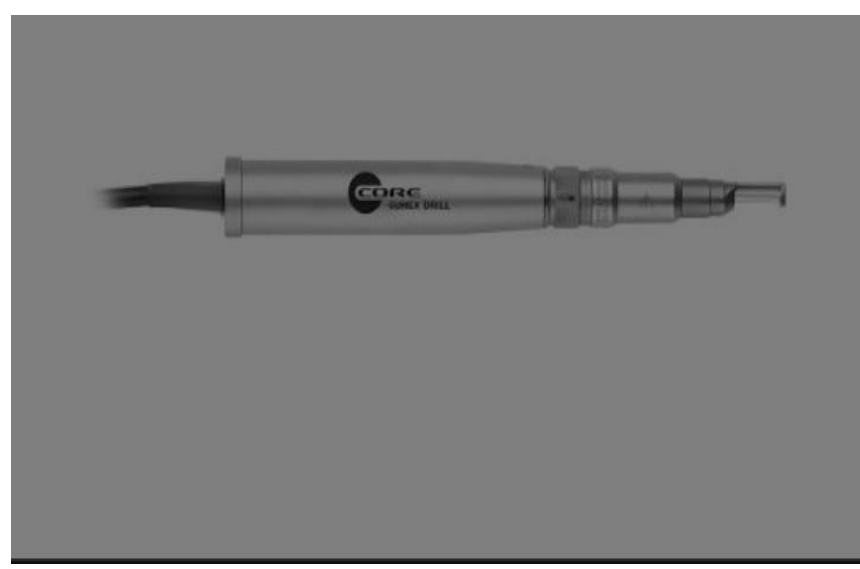

Figure 1 Neuro drill

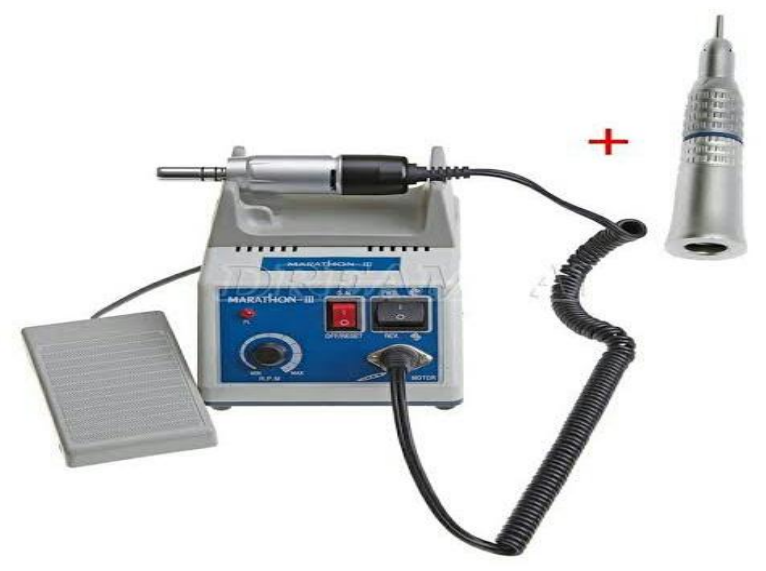

Figure 2 Dental micro drill system with hand piece 


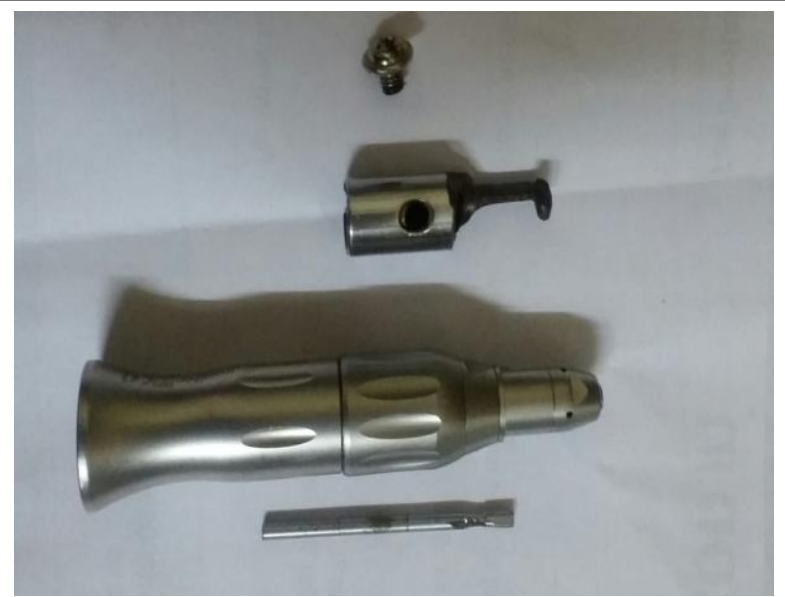

Figure 3 Custom made duraguard with fixing screw,dental hand piece,straight fluted side cutting cylindrical $2.35 \mathrm{~mm}$ friction grip dental burr

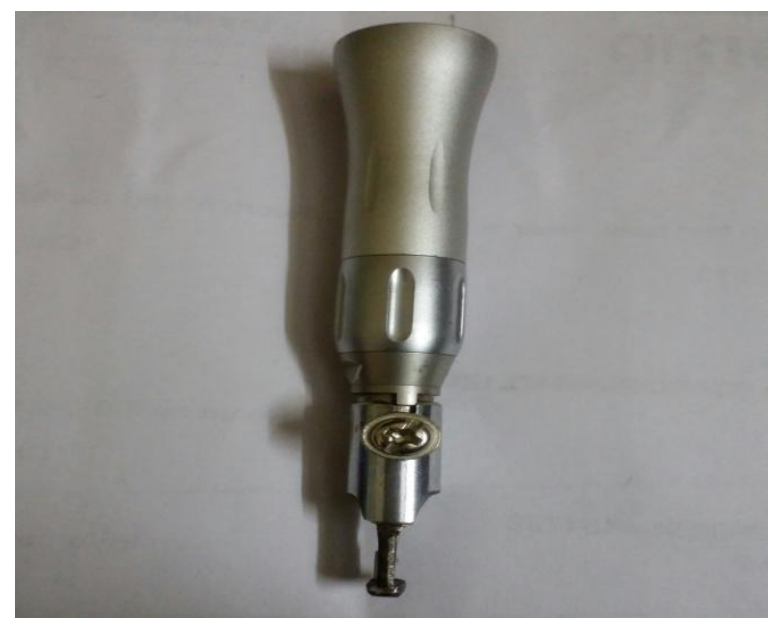

Figure 4 Dental hand piece with custom made dura guard - front view

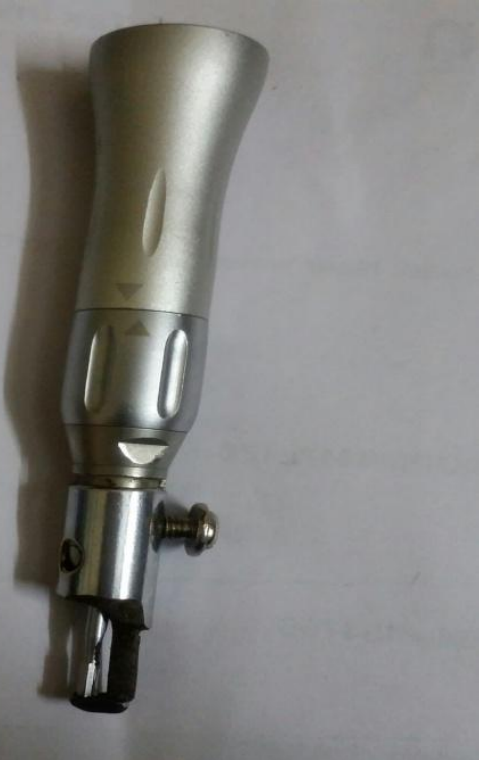

Figure 5 Coustom made dental hand piece with dura guard and burr-side view

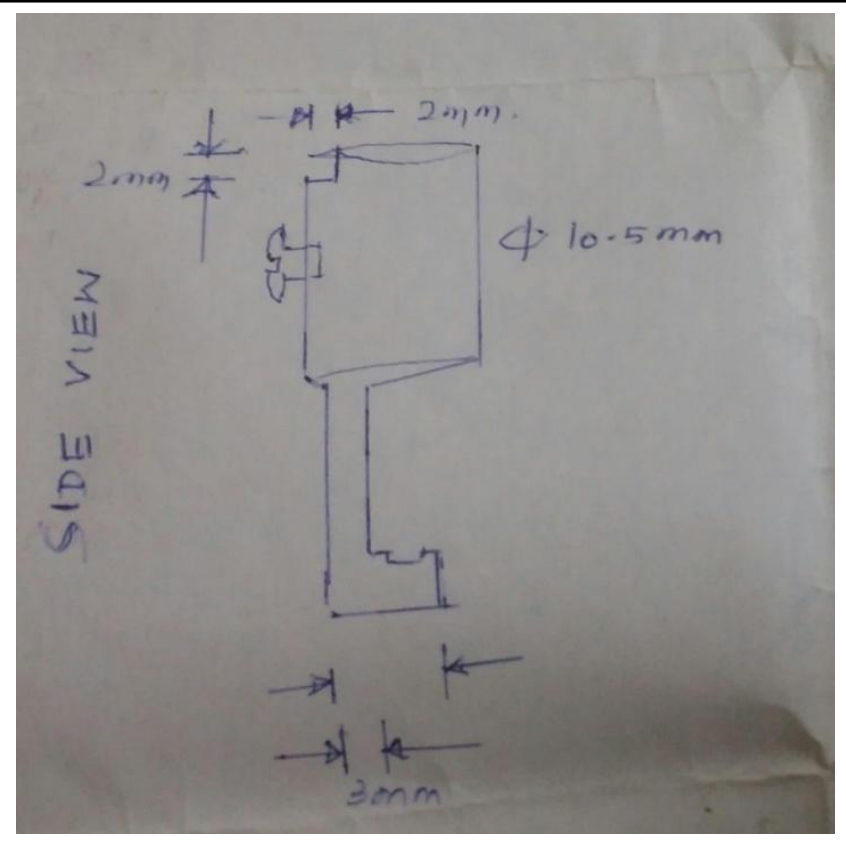

Figure 6 Dura guard side view dimensions

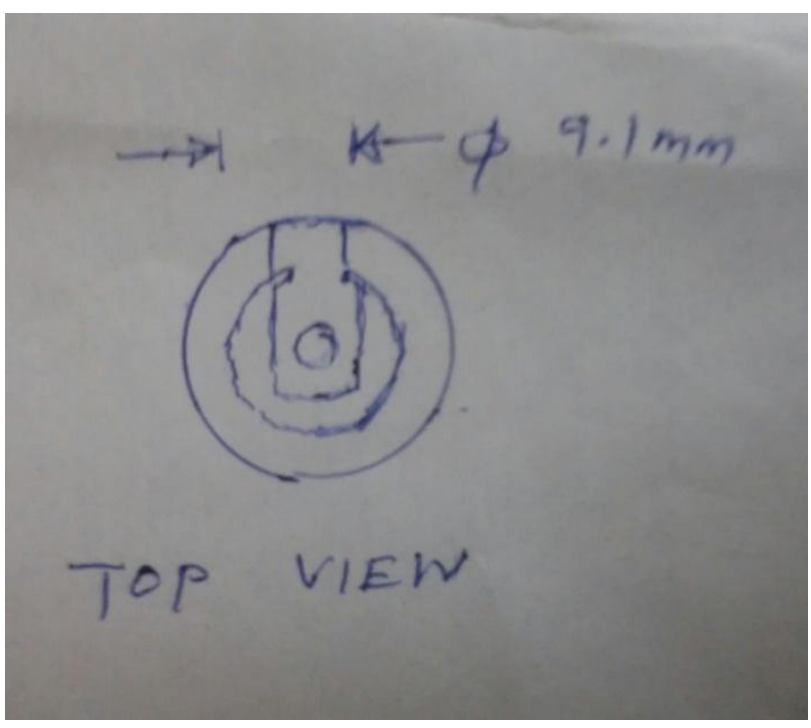

Figure 7 Dura guard top view dimension

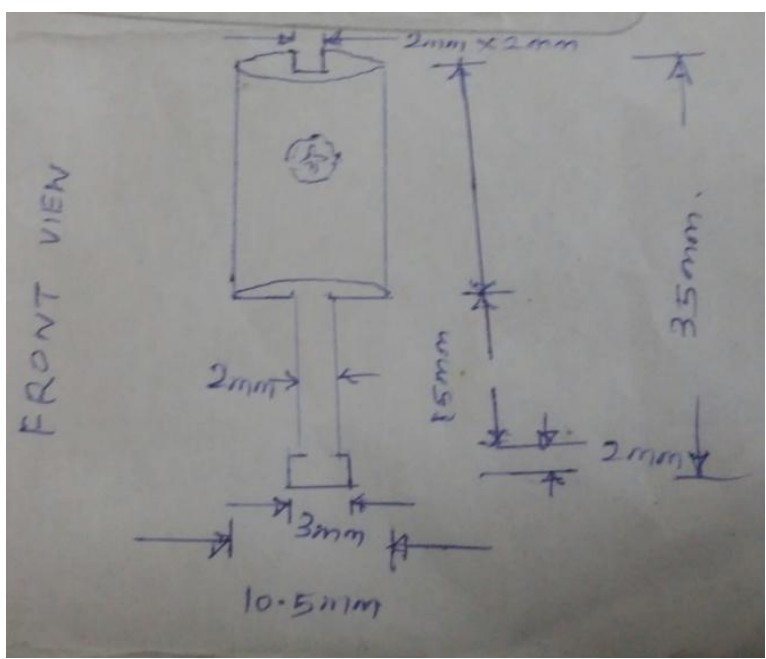

Figure 8 Dura guard front view dimensions 


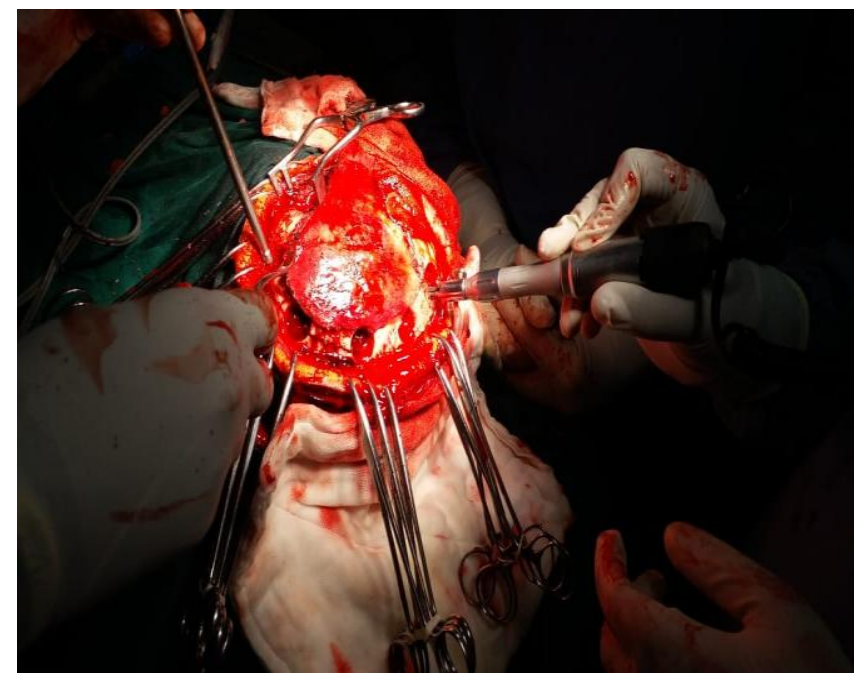

Figure 9 Custom made craniotome with dental micodrill in neurosurgery

\section{Discussion}

History shows that around the era of 4000 B.C. the first hole was applied on a human's brain with a drill. ${ }^{[1]}$ The oldest cranial drilling instrument was founded in France, and adapted by the Ancient Romans, Egyptians, and the Mesoamerican civilization

The first craniotome was designed and created by John H. Bent, a mechanical engineer and owner of Standard Pneumatic Motor Company, under contract with Hall Air Instruments of Santa Barbara, California. When Hall was subsequently acquired by $3 \mathrm{M}$ Company (which was then actively developing and marketing surgical instruments), the $3 \mathrm{M}$ Craniotome became widely used in neurosurgery, replacing the Gigli saw (manually pulled saw wires) as the primary means of opening the skull for access to the brain for surgical procedures. Bent designed the original Craniotome around a small, lightweight, very high speed (approximately 70,000 rpm) pneumatic turbine motor he had invented the first craniotomes ever used in surgery was used to operate on John Bent himself, who required lifesaving neurosurgery for a brain abscess that was discovered around the time the tool was being put into production. Pathetic situation is still manual Hudson drill also not available in developing countries like india particularly in district hospitals.
The advantages of dental micro drilldrill are 1 . Low cost around 5000 INR which is 3 times cheaper than good quality Hudson brace, 20 times cheaper than Indian made cranial drill system and 200 times cheaper than foreign made neuro drill system.2. The cost for making of the dural guard is only 100 rupees. 3 . The 2.35 friction grip burr used in this study is only 50 (metal burr) - 150 (carbide burr) rupees 4 . autoclavable clinical hand piece along with custom made dural guard. The major disadvantage is reproducibility by other surgeons.

Source of funding: None

Conflicts of interest: None

\section{References}

1. Cohut, Maria. "Skull-drilling: The ancient roots of modern neurosurgery". Medical News Today. Retrieved 28 September 2018.

2. Wylie, Robin. "Why our ancestors drilled holes in each other's skulls". BBC. Retrieved 10 November 2018.

3. Ferreira, Becky. "Madness Stones to New Age Medicine: A History of Drilling Holes in Our Heads". Motherboard. Retrieved 10 November 2018.

4. Gross, Charles G. "Trepanation from the Paleolothic to the internet" (PDF). Retrieved 10 November 2018.

5. Liss, Sam T. "Safe cranial drilling device". Harvard Office of Technology Development. Retrieved 10 November 2018.

6. SRM University. "Surgical driller" (PDF). Retrieved 10 November 2018.

7. Villaluz, Kathleen (2017-05-08). "This Robotic Drill Can Perform Complex Cranial Surgeries 50 Times Faster". Interesting Engineering. Retrieved 1 November 2018.

8. "CRANIAL PERFORATOR". evonos. Retrieved 12 November 2018.

9. Wikimedia Commons has media related to Dental drills and bits. 
10. "Dental More Gentle with Painless 'Drillings' and Matching Fillings", Food and Drug Administration (FDA) Consumer magazine, May-June 1999

11. "Dental More Gentle with Painless 'Drillings' and Matching Fillings", Food and Drug Administration (FDA) Consumer magazine, May-June 1999

12. "'Robotic' dental drill to be tested on humans", New Scientist, 20 April 2005

13. "Dental Technology and Research", Canadian Dental Association Web Site (PDF file)

14. "History of Dentistry", American Dental Association Web Site. 